\title{
A comparison of TEQ contributions from PCDDs, PCDFs and dioxin-like PCBs in sewage sludges from Catalonia, Spain
}

\author{
E. Eljarrat*, J. Caixach and J. Rivera
}

Mass Spectrometry Laboratory, Ecotechnologies Department, I.I.Q.A.B., C.S.I.C., Jordi

Girona 18-26, 08034 Barcelona, Spain. Fax: 34-93-2045904, e-mail: eeeeco@cid.csic.es

\section{Abstract}

Eight sewage sludges from rural, urban and industrial waste water treatment plants (WWTPs) in Catalonia (Spain) were analysed for polychlorinated dibenzo-p-dioxins (PCDDs), dibenzofurans (PCDFs) and biphenyls (PCBs) to determine the present levels of contamination. A method based on an automated cleanup system followed by an isotope-dilution highresolution mass spectrometric analysis was employed. Total Toxicity Equivalent (WHO-TEQ) values were calculated using the Toxicity Equivalent Factors (WHO-TEFs) proposed by WHO for dioxin-like PCBs, PCDDs and PCDFs. The WHO-TEQ ${ }_{\mathrm{PCDD} / \mathrm{F}}$ values for these samples ranged from 4.9 to $20.8 \mathrm{pg} / \mathrm{g}$ d.w., with a mean value of $9.3 \mathrm{pg} / \mathrm{g}$ d.w., whereas WHO-TEQPCB levels ranged between 1.9 and $6.6 \mathrm{pg} / \mathrm{g}$ d.w., with a mean value of $4.2 \mathrm{pg} / \mathrm{g}$ d.w. The WHO-TEQ ${ }_{\mathrm{PCB}}$ contribution varied from $13 \%$ to $50 \%$, suggesting that PCB contribution on the toxicity of the samples must be taken into account. Moreover, these contemporary PCDD, PCDF and PCB concentrations were compared with previous data obtained from sewage sludge samples collected during the 80 s. Our findings show that contemporary PCDD, PCDF and PCB levels have declined since the 80 s.

Key words - Dioxins, Furans, PCBs, Sewage Sludge, Spain 


\section{Introduction}

The European Directive on wastewater treatment (COM 91/271) requires the installation of treatment systems in all populations exceeding 2000 inhabitants before the year 2005 . Estimates for the year 2000 predict an increase of $185 \%$ in sewage sludge production in Spain, which means about 250,000 tons per year in Catalonia (Northeast of Spain). Different sludge management techniques were used, being land application one of the most common methods of sewage sludge disposal. In many countries there is a continuous discussion on the significance of sewage sludge fertilization of cultivated land in terms of soil contamination. The contamination of polychlorinated dibenzo- $p$-dioxins (PCDDs) and polychlorinated dibenzofurans (PCDFs) in sewage sludge is well documented. Analytical results have been reported from the United States (Tiernan et al., 1997), Germany (Gihr et al., 1991; Hagenmaier et al., 1992), Sweden (Broman et al., 1990), the United Kingdom (Sewart et al., 1995) and Spain (Eljarrat et al., 1997 and 1999). However, no EU Directive exist for organic contaminants in sludges at present. In Germany in 1992, the Ordinance on Sewage Sludge established a limit of $100 \mathrm{ng}$ TEQ/Kg dry weight (d.w.) of sludge for PCDDs and PCDFs and $200 \mu \mathrm{g} / \mathrm{Kg}$ d.w. for seven indicator polychlorinated biphenyl (PCB) congeners $(28,52,101,118,138,153$ and 180) for agricultural purposes.

From the late 1970s to the present, a great deal of emphasis has been placed on the analysis of PCDDs and PCDFs. Recently, special attention has been focused on a few selected PCB congeners which are stereo-chemically similar to 2378-tetraclorodibenzo-p-dioxin (2378TCDD) and have toxicological properties similar to 2378-TCDD. These congeners are potent inducers of liver microsomal aryl hydrocarbon hydroxylase $(\mathrm{AHH})$ and are thus referred to as dioxin-like PCBs. The World Health Organisation (WHO) has identified 12 PCBs as being similar in toxicity to PCDDs and PCDFs. These dioxin-like PCB congeners are classified 
according to the number of chlorines in the ortho-position: 4 non-ortho (IUPAC Nos. 77,81,126 and 169) and 8 mono-ortho (IUPAC Nos. 105,114,118,123,156,157,167 and 189) (Berg et al., 1998). All of these twelve congeners, as well as the 17 toxic PCDD/F congeners, have an assigned Toxicity Equivalence Factor (WHO-TEF).

The aim of this study was to determine the dioxin-like PCB levels in sewage sludges from Catalonia, and to compare them with the PCDD and PCDF concentrations in order to evaluate the contribution of each contaminant in the total toxicity of the samples. A further objective was to compare the PCB, PCDD and PCDF levels in these sludges with results obtained from samples taken in the 80s (Eljarrat et al., 1997 and 1999) in order to detect temporal trends.

\section{Experimentally}

\subsection{Sampling sites}

Eight sewage sludge samples were collected in 2000 from different wastewater treatment plants (WWTPs) in Catalonia. These WWTPs are located in the villages of Figueres, Olot, Roses, Tossa, Lleida, Reus, Vilafranca and Mataró (NE Spain). The sewage sludges analysed were from rural, urban and industrial origin.

\subsection{Chemicals}

EPA Method 1613 standard solutions (CS-1 to CS-5, LCS and ISS) and WP standard solutions (CS-1 to CS-7, LCS and ISS) were purchased from Wellington Labs. (Guelph, Ontario, Canada) for instrument calibration, quantification and recovery of PCDDs/PCDFs and dioxinlike PCBs, respectively. Individual standard solutions (MBP-28, MBP-37, MBP-52, MBP-101, MBP-153 and MBP-180, Wellington Labs., Guelph, Ontario, Canada) were used to prepare 
mixture solutions for indicator PCB analyses. Solvents (acetone, dichloromethane, toluene, ethyl acetate, n-hexane and cyclohexane) for organic trace analysis were purchased from Merck (Darmstadt, Germany).

\subsection{Extraction and clean-up}

A method tested previously for the simultaneous analysis of PCBs, PCDDs and PCDFs was used in this study (Eljarrat et al., 2001). The samples were air dried and manually ground before extraction. Ten gram d.w. sludge samples were spiked with known amounts of ${ }^{13} \mathrm{C}$ PCDDs, ${ }^{13} \mathrm{C}-\mathrm{PCDF}$ and ${ }^{13} \mathrm{C}-\mathrm{PCB}$ (Wellington Labs., Guelph, Ontario, Canada) and extracted in a Soxhlet apparatus for 48 hours with $300 \mathrm{~mL}$ of toluene of pesticide grade (Merck). After extraction, the crude extracts were transferred to hexane and treated with concentrated $\mathrm{H}_{2} \mathrm{SO}_{4}$, followed by cleanup procedure. Purification was accomplished by an automated cleanup system based on the use of multilayer silica, basic alumina and AX-21 carbon adsorbents. During this automated cleanup procedure, two fractions were collected. The first contains mono-ortho and di-ortho PCBs, and the second fraction contains non-ortho PCBs, PCDDs and PCDFs. The whole process was accomplished in approx one hour. Prior to HRGC-HRMS analysis, extracts were concentrated to incipient dryness prior to the addition of the recovery standards (ISS solutions).

\subsection{Instrumental analysis}

Purified extracts were analysed by HRGC/HRMS on an AutoSpec-Ultima mass spectrometer (Micromass, Manchester, UK) coupled with a GC 8000 series gas chromatograph (Carlo Erba Instruments, Milan, Italy). A DB-5 (J\&W Scientific, Folsom, CA, USA) fused-silica capillary column (60m x $0.25 \mu \mathrm{m}$ i.d., $0.25 \mathrm{~mm}$ film thickness) was used with helium as carrier gas at a linear velocity of $28 \mathrm{~cm} / \mathrm{s}$. The PCB analyses were based on the U.S. EPA Method for 
PCB determinations (USEPA Method 1668). The temperature programme was from $90^{\circ} \mathrm{C}$ (held for $1 \mathrm{~min}$.) to $180^{\circ} \mathrm{C}$ (held for $1 \mathrm{~min}$.) at $20^{\circ} \mathrm{C} / \mathrm{min}$., and then from $180^{\circ} \mathrm{C}$ to $300^{\circ} \mathrm{C}$ (held for 10 $\min$.) at $3^{\circ} \mathrm{C} / \mathrm{min}$., using the splitless injection mode. The HRGC/HRMS operating conditions were as follows: ion source and interface temperatures, $250^{\circ} \mathrm{C}$ and $275^{\circ} \mathrm{C}$, respectively; ionization energy, $35 \mathrm{eV}$ (electron ionization mode) and trap current $300 \mathrm{~mA}$. The resolving power was kept at 10000 (10\% valley definition). The PCDD and PCDF analyses were based on the U.S. EPA Method for PCDD/F determinations (USEPA Method 1613). The temperature programme was from $140^{\circ} \mathrm{C}$ (held for $1 \mathrm{~min}$.) to $200^{\circ} \mathrm{C}$ (held for $1 \mathrm{~min}$.) at $20^{\circ} \mathrm{C} / \mathrm{min}$., and then from $200^{\circ} \mathrm{C}$ to $300^{\circ} \mathrm{C}$ (held for $20 \mathrm{~min}$.) at $3^{\circ} \mathrm{C} / \mathrm{min}$., using the splitless injection mode. The HRGC/HRMS operating conditions were the same that used for PCB analyses.

Quantification was carried out by the isotopic dilution method. Relative response factors (RRFs) for the individual isomers were obtained by analysing standard solution mixtures (CS solutions). The recoveries of labeled standards were calculated using mixtures of labeled compounds (ISS solutions) added before the HRGC-HRMS analysis. The data achieved were evaluated employing defined analytical criteria. The acceptance criteria for data include: chlorine isotope ratio within $\pm 15 \%$ of the correct ratio, peak maxima retention time within two seconds and peak responses at least three times the background noise level (Eljarrat et al., 1995).

\section{Results and discussion}

\subsection{PCDD/PCDF concentrations}

Table 1 provides PCDD and PCDF results of the sewage sludge samples analysed. We report the concentrations of all 2378-substituted PCDD/PCDF congeners, the dioxin, furan and total WHO-TEQ values and the dioxin/furan ratio ( $\mathrm{R}_{\mathrm{TEQ} P C D D / T E Q}$ PCDFs $)$. The recovery of the ${ }^{13} \mathrm{C}$ labeled compounds in all cases ranged from 57 to $88 \%$, indicating that the PCDD/PCDF 
extraction and cleanup worked properly.

A series of PCDDs and PCDFs were identified in the samples studied. The seven 2,3,7,8substituted PCDDs and the ten 2,3,7,8-substituted PCDFs were normalized by multipliying their measured concentrations by the appropriate WHO-TEFs (Berg et al., 1998). The sum of these products yields the WHO-TEQ $\mathrm{PCDD} / \mathrm{F}$ values which express these analyte concentrations as a single number, equivalent to that of a toxicity derived exclusively from 2,3,7,8-TCDD. The results for WHO-TEQPCDD/F ranged from 4.90 to $20.8 \mathrm{pg} / \mathrm{g}$ d.w., with a mean value of $9.32 \mathrm{pg} / \mathrm{g}$ d.w. The variation in the WHO-TEQ concentration may be attributed to varying loads during the sample collection period at the different WWTPs. The highest WHO-TEQ level was found to be that of Figueres (20.8 pg WHO-TEQ/g d.w.), followed by Mataró (14.1 pg WHO-TEQ/g d.w.)> Reus (8.06 pg WHO-TEQ/g d.w.) $>$ Roses = Vilafranca (7.18 pg WHO-TEQ/g d.w.) > Lleida (6.92 pg WHO-TEQ/g d.w.) > Olot (5.43 pg WHO-TEQ/g d.w.) > Tossa (4.90 pg WHO-TEQ/g d.w.). All the calculated WHO-TEQs were far from the limit set at $100 \mathrm{pg} \mathrm{TEQ} / \mathrm{g}$ d.w. for agricultural purposes.

All the samples were dominated by OCDD and OCDF, and contained relatively high concentrations of HpCDDs and HpCDFs. The ratio $\mathrm{R}_{\mathrm{TEQ}} \mathrm{PCDD} / \mathrm{TEQ}$ PCDF was calculated, and the values ranged between 0.5 and 1.4, with a mean value of 1.0. Generally, sewage sludge samples are characterized by a $\mathrm{R}_{\mathrm{TEQ} \text { PCDD/TEQ PCDF }}>1$ (Eljarrat et al., 1997 and 1999). However, from the eight samples analysed in our study, four presented a $\mathrm{R}_{\mathrm{TEQ} \text { PCDD/TEQ PCDF }}<1$.

\subsection{PCB concentrations}

Table 2 gives PCB results of the sewage sludge samples collected for this study. We report the concentrations of the twelve selected dioxin-like PCBs, as well as the seven indicator PCBs, and WHO-TEQPCB values. The recovery of the ${ }^{13} \mathrm{C}$-labeled compounds in all cases ranged from 56 to $98 \%$, indicating that the PCB extraction and cleanup worked properly. 
The highest indicator PCB concentrations were found to be those of Vilafranca $(72.5 \mathrm{ng} / \mathrm{g}$ d.w.), followed by Roses (49.9 ng/g d.w.) > Lleida (48.7 ng/g d.w.) > Reus (40.0 ng/g d.w.) > Tossa (37.1 ng/g d.w.) > Mataró (28.0 ng/g d.w.) > Figueres (23.4 ng/g d.w.) > Olot (22.7 ng/g d.w.). Thus, the rank of contamination established for PCDD/F deviated considerably, and no correlation between the two families of toxic compounds could be established. All the calculated PCB levels were far from the limit set at $200 \mathrm{ng} / \mathrm{g} \mathrm{d.w}$. for agricultural purposes.

With regard to dioxin-like PCBs, it should be pointed that the concentrations of monoortho PCBs were higher than those of the non-ortho PCBs. The PCB \# 118 was the predominant mono-ortho congener, followed by PCB \# 105 and 167. In the case of non-ortho PCBs, PCB \# 77 was the congener that exhibited the highest values. The twelve dioxin-like PCBs were normalized by multiplying their measured concentrations by the appropriate WHO-TEFs (Berg et al., 1998). The sum of these products yields WHO-TEQ TEQ ${ }_{\mathrm{PCB}}$ was that of Vilafranca (6.62 pg WHO-TEQ/g d.w.), followed by Mataró (6.30 pg WHOTEQ/g d.w.) > Roses (4.75 pg WHO-TEQ/g d.w.) > Lleida (4.63 pg WHO-TEQ/g d.w.) > Tossa (3.42 pg WHO-TEQ/g d.w.) > Reus (3.26 pg WHO-TEQ/g d.w.) > Figueres (3.00 pg WHOTEQ/g d.w.) $>$ Olot (1.86 pg WHO-TEQ/g d.w.). This rank of contamination deviated with the rank of contamination found for PCDDs/Fs, but also with that of indicator PCBs. All the calculated WHO-TEQs were far from the limit set at $100 \mathrm{pg}$ TEQ/g d.w. for agricultural purposes.

\subsection{TEQ contribution of PCDDs/Fs and PCBs}

The total WHO-TEQ (WHO-TEQPCDD/F + WHO-TEQ $\left.{ }_{\mathrm{PCB}}\right)$ values were calculated for the eight sewage sludge samples. The data obtained were: $23.8 \mathrm{pg} \mathrm{WHO-TEQ/g} \mathrm{d.w.} \mathrm{for} \mathrm{Figueres,}$ 7.29 pg WHO-TEQ/g d.w. for Olot, 11.9 pg WHO-TEQ/g d.w. for Roses, $8.32 \mathrm{pg}$ WHO-TEQ/g d.w. for Tossa, $11.6 \mathrm{pg}$ WHO-TEQ/g d.w. for Lleida, $11.3 \mathrm{pg} \mathrm{WHO-TEQ/g} \mathrm{d.w.} \mathrm{for} \mathrm{Reus,} 13.8$ 
pg WHO-TEQ/g d.w. for Vilafranca and 20.4 pg WHO-TEQ/g d.w. for Mataró. Thus, even taking in account the contribution of dioxin-like PCBs in the total WHO-TEQ of the samples, the values were below the limit set at $100 \mathrm{pg} \mathrm{TEQ} / \mathrm{g} \mathrm{d.w}$. for agricultural purposes.

An investigation into relative abundances based on WHO-TEQs between PCDDs/Fs and dioxin-like PCBs in sewage sludge samples was carried out. The Figure 1 shows the percentage contribution to the total WHO-TEQ from non-ortho and mono-ortho, and PCDDs/Fs. As can be seen, the contribution of each family of compounds is different. The general trend is that PCBs are found at higher concentrations than the PCDDs/Fs in the same sample (at least, one order of magnitude). Based on the WHO-TEFs used, however, the percentage contribution to the total WHO-TEQ from PCBs can be significant but is usually lower than the PCDDs/Fs contribution. The contribution of PCDDs and PCDFs in the total WHO-TEQ ranged between 50 and $87 \%$, whereas that of dioxin-like PCBs ranged from 13 to 50\%. Moreover, in all the cases the largest contribution to WHO-TEQPCB came from the non-ortho PCBs (from 62 to $91 \%$ ), followed by the mono-ortho PCBs (from 9 to 38\%) . PCB congeners 126, 118 and 156 were the predominant contributors to WHO-TEQPCBs in sludge samples.

\subsection{Temporal trends in PCDD, PCDF and PCB levels}

A previous study on the PCDD and PCDF levels in sewage sludges from different WWTPs from Catalonia (Spain) showed that PCDD/F concentrations of sewage sludges collected in the 90 s were considerably lower than those found in sewage sludges collected during the $80 \mathrm{~s}$. The calculated TEQ $\mathrm{PCDD/F}$ values in the samples collected in the $80 \mathrm{~s}$ ranged from 29 to $8300 \mathrm{pg} / \mathrm{g}$ d.w. with a mean value of $620 \mathrm{pg} / \mathrm{g}$ d.w., whereas sludges collected during the $90 \mathrm{~s}$ showed levels between 7 and 160 pg/g d.w., with a mean value of 55 pg/g d.w. (Eljarrat et al., 1999). In the present study, we reported concentrations of sludges collected in 2000 , and a slightly decline was observed when comparing with levels during the 90 s. It cannot be 
established from our limited study whether this difference reflects a general decline in PCDDs and PCDFs in sewage sludges of Catalonia over the last years, or whether the lower levels observed here simply reflect the characteristics of the WWTPs surveyed here. Thus, in Table 3 we presented a comparison of the results obtained only for the samples from the same WWTP at different times. The PCDD and PCDF concentrations show a marked decline since the 80s. When comparing PCDD/F levels from sludges sampled in the 90s with those of samples from the 2000, a general slight decline was also observed. The reduction was more pronounced in the samples with the highest levels in the 90s than in those with low levels. In the 90s sampling, the sludges from the WWTPs of Tossa and Vilafranca presented levels upon the limit set at $100 \mathrm{pg}$ TEQ/g d.w., whereas very low levels were found in the sampling carried out during the 2000: 4.90 and $7.18 \mathrm{pg}$ TEQ/g d.w., respectively.

Regarding the PCB levels, the results obtained in this study were compared with those obtained in previous studies (Pauné et al., 1994; Eljarrat et al., 1997). Eljarrat et al. presented the PCB concentrations in seven sludge samples from Catalonian WWTPs collected during the $80 \mathrm{~s}$, and found levels ranging from 35 to $121 \mathrm{ng} / \mathrm{g} \mathrm{d.w.,} \mathrm{with} \mathrm{a} \mathrm{mean} \mathrm{value} \mathrm{of} 76 \mathrm{ng} / \mathrm{g} \mathrm{d.w}$. Pauné et al. reported the PCB levels in six different sewage sludges from Catalonia during the $90 \mathrm{~s}$. The values ranged from 69 to $653 \mathrm{ng} / \mathrm{g}$ d.w. with a mean value of $332 \mathrm{ng} / \mathrm{g}$ d.w. In the present study, we reported concentrations of sludges collected in 2000, and the levels ranging between 23 and $72 \mathrm{ng} / \mathrm{g}$ d.w., with a mean value of $40 \mathrm{ng} / \mathrm{g}$ d.w. Thus, the similar behaviour observed for PCDDs and PCDFs was also detected for the PCBs. The lower levels detected in the contemporary sludges could reflect a general decline in PCDD/F inputs to the environment, owing to tighter controls on PCB and PCP use and disposal.

\section{Conclusions}


In the light of our findings the following conclusions can be drawn. a) PCDDs and PCDFs were detected in all the sewage sludges analysed, and a range of contamination from 4.9 to $20.8 \mathrm{pg}$ WHO-TEQ/g d.w. was established. b) Dioxin-like PCBs were also detected in all the samples, with levels ranging between 1.9 and $6.6 \mathrm{pg}$ WHO-TEQ/g d.w. c) All the concentrations were below the limits set by the German Ordinance on Sewage Sludge for agricultural purposes. d) An assessment of the relative contribution of PCDDs/Fs and dioxin-like PCBs in the different sewage sludge samples was carried out. The contribution of dioxin-like PCBs varied from 13\% to $50 \%$. This work suggests that complete characterization of the TEQ values demands the measurement of PCDDs and PCDFs, but also of the dioxin-like PCBs. e) A general decline in PCDD, PCDF and PCB levels was observed since the 80s.

\section{Acknowledgements}

The authors are indebted to Dr. Saña and to Agència Catalana de l'Aigua (Generalitat de Catalunya) for kindly providing sewage sludge samples. The assistance of M.A.Adrados, M.G.Martrat, A.Monjonell and J.Sauló is also gratefully acknowledged.

\section{References}

Berg, M., Birnbaum, L., Bosveld, A.T.C., Brunstrom, B., Cook, P., Feeley, M., Giesy, J.P., Hanberg, A., Hasegawa, R., Kennedy, S.W., Kubiak, T., Larsen, J.C., Leeuwen, F.X.R., Liem, A.K.D., Nolt, C., Peterson, R.E., Poellinger, L., Safe, S., Schrenk, D., Tillitt, D., Tysklind, M., Younes, M., Waern, F., Zacharewski, T., 1998. Environ. Health Perspect. $106,775$.

Broman, D., Näf, C., Rolff, C. and Zebühr, Y., 1990. Analysis of polychlorinated dibenzo-p- 
dioxins (PCDD) and polychlorinated dibenzofurans (PCDF) in soil and digested sewage sludge from Stockholm, Sweden. Chemosphere 21, 1213-1220.

COM 91/271. Commission of the European Communities. Council Directive concerning Urban Wastewater Treatment. Official Journal of the European Communities L135/40-52.

Eljarrat, E., Casanovas, J., Muro, R., Huguet, X., Caixach, J and Rivera, J., 1995. Determination of chlorinated dioxins and furans by high resolution gas chromatography coupled to mass spectrometry: comparative study of LRMS and HRMS. Química Analítica 14, 89-95.

Eljarrat, E., Caixach, J. and Rivera, J., 1997. Effects of sewage sludges contaminated with polychlorodibenzo-p-dioxins, dibenzofurans and biphenyls on agricultural soils. Environ. Sci. Technol. 31, 2765-2771.

Eljarrat, E., Caixach, J. and Rivera, J., 1999. Decline in PCDD and PCDF levels in sewage sludges from Catalonia (Spain). Environ. Sci. Technol. 33, 2493-2498.

Eljarrat, E., Sauló, J., Monjonell, A., Caixach, J. and Rivera, J., 2001. Evaluation of an automated cleanup system for the isotope dilution high-resolution mass spectrometric analysis of PCBs, PCDDs and PCDFs in foodstuffs samples. J. of Chromatogr. A (submited).

Gihr, R., Klöpffer, W., Rippen, G., Partscht, H., Stoll, U. and Müller, J., 1991. Investigations on potential sources of polychlorinated dibenzo-p-dioxins and dibenzofurans in sewage sludges. Chemosphere 23, 1653-1659.

Hagenmaier, H., She, J., Benz, T., Dawidowski, N., Düsterhöft, L. and Lindig, C., 1992. Analysis of sewage sludge for polyhalogenated dibenzo-p-dioxins, dibenzofurans and diphenylethers. Chemosphere 25, 1457-1462.

Pauné, F., Rivera, J., Espadaler, I. and Caixach, J., 1994. Determination of polychlorinated biphenyls in sewage sludges from Catalonia (N.E.Spain) by high-resolution gas chromatography with electron-capture detection. J. of Chromatogr. A 684, 289-296. 
Sewart, A., Harrad, S.J., McLachlan, M.S., McGrath, S.P. and Jones, K.C., 1995. PCDD/Fs and non-o-PCBs in digested U.K. sewage sludges. Chemosphere 30, 51-67.

Tiernan, T.O., Garret, J.H., Solch, J.G., VanNess, G.F., Wagel, D.J. and Rukunda, F., 1997. Polychlorinated dibenzo-p-dioxins (PCDDs) and polychlorinated dibenzofurans (PCDFs) in sewage sludges from rural and urban/industrial wastewater treatment plants (WWTPs). Organohalogen Compd. 32, 98-102.

U.S.Environmental Protection Ag., EPA, Method 1613: “Tetra through octa chlorinated dioxins and furans by isotopic dilution HRGC-HRMS.”, Washington DC, 1994.

U.S.Environmental Protection Ag., EPA Method 1668: "Toxic Polychlorinated Biphenyls by Isotope Dilution High Resolution Gas Chromatography / High Resolution Mass Spectrometry.”, Office of Science and Technology, March 1997. 
Table 1.

Concentrations of PCDDs and PCDFs (expressed in $\mathrm{pg} / \mathrm{g}$ dry weight) in sewage sludge samples analysed

\begin{tabular}{|c|c|c|c|c|c|c|c|c|}
\hline & Figueres & Olot & Roses & Tossa & Lleida & Reus & Vilafr. & Mataró \\
\hline 2378-TCDD & n.d. & 0.12 & 0.23 & 0.15 & 0.32 & 0.35 & 0.39 & 0.20 \\
\hline 12378-PeCDD & 5.77 & 1.43 & 2.86 & 1.81 & 2.60 & 4.22 & 4.55 & 2.28 \\
\hline 123478-HxCDD & 2.74 & 0.45 & 0.60 & 0.34 & 1.05 & 0.73 & 0.64 & 0.66 \\
\hline 123678-HxCDD & 8.37 & 2.86 & 4.23 & 3.06 & 3.89 & 0.84 & 0.73 & 5.08 \\
\hline 123789-HxCDD & 7.73 & 1.64 & 2.27 & 1.82 & 2.31 & 2.12 & 2.03 & 2.23 \\
\hline 1234678-HpCDD & 108 & 52.8 & 93.1 & 69.2 & 12.8 & 70.3 & 63.0 & 129 \\
\hline OCDD & 852 & 527 & 785 & 609 & 943 & 647 & 556 & 1603 \\
\hline 2378-TCDF & 46.6 & 7.38 & 8.44 & 4.72 & 11.2 & 7.64 & 7.86 & 22.3 \\
\hline 12378-PeCDF & 6.47 & 1.05 & 2.48 & 1.86 & 1.22 & 2.28 & 1.51 & n.d. \\
\hline 23478-PeCDF & 12.4 & 1.86 & 2.28 & 1.39 & 1.92 & 2.23 & 1.89 & 5.03 \\
\hline 123478-HxCDF & 12.5 & 3.92 & 3.19 & 2.47 & 3.51 & 4.10 & 3.07 & 2.62 \\
\hline 123678-HxCDF & 5.82 & 1.34 & 1.49 & 1.05 & 3.54 & 4.13 & 3.09 & 0.92 \\
\hline 234678-HXCDF & 6.90 & 2.72 & 2.12 & 1.46 & 1.89 & 1.78 & 1.76 & 4.85 \\
\hline 123789-HxCDF & 0.22 & 0.10 & n.d. & n.d. & 0.31 & 0.42 & 0.22 & n.d. \\
\hline 1234678-HpCDF & 31.4 & 38.6 & 24.6 & 21.3 & 32.4 & 39.7 & 25.0 & 229 \\
\hline 1234789-HpCDF & 1.44 & 1.37 & 1.04 & 0.68 & 1.92 & 2.41 & 1.01 & 1.48 \\
\hline OCDF & 70.5 & 123 & 47.5 & 47.1 & 107 & 450 & 88.5 & 1173 \\
\hline WHO-TEQ Dioxins & 6.69 & 2.39 & 4.09 & 2.88 & 3.41 & 4.17 & 4.19 & 5.03 \\
\hline WHO-TEQ Furans & 14.1 & 3.04 & 3.09 & 2.02 & 3.51 & 3.89 & 2.99 & 9.06 \\
\hline $\mathrm{R}_{\mathrm{TEQ} \text { PCDD/TEQ PCDF }}$ & 0.48 & 0.79 & 1.32 & 1.43 & 0.97 & 1.07 & 1.40 & 0.56 \\
\hline $\mathrm{WHO}^{-T E Q_{\mathrm{PCDD} / \mathrm{F}}}$ & 20.8 & 5.43 & 7.18 & 4.90 & 6.92 & 8.06 & 7.18 & 14.1 \\
\hline
\end{tabular}


Table 2

Dioxin-like PCB concentrations (pg/g dry weight) and indicator PCB levels (ng/g dry weight) corresponding to the different sewage sludges studied

\begin{tabular}{|c|c|c|c|c|c|c|c|c|}
\hline & Figueres & Olot & Roses & Tossa & Lleida & Reus & Vilafr. & Mataró \\
\hline \multicolumn{9}{|l|}{ Dioxin-like } \\
\hline PCB \# 81 & 14.9 & 8.47 & 23.2 & 16.0 & 16.4 & 18.7 & 15.2 & 14.4 \\
\hline PCB \# 77 & 333 & 215 & 448 & 346 & 315 & 406 & 381 & 207 \\
\hline PCB \# 126 & 23.2 & 13.8 & 35.2 & 24.7 & 35.6 & 23.7 & 40.2 & 49.9 \\
\hline PCB \# 169 & 5.11 & 6.72 & 6.52 & 4.02 & 7.30 & 5.75 & 5.44 & 74.2 \\
\hline PCB \# 105 & 1103 & 658 & 1690 & 1656 & 1474 & 1182 & 4759 & 817 \\
\hline PCB \# 114 & 102 & 32.4 & 162 & 87.6 & 77.7 & 82.2 & 209 & 76.6 \\
\hline PCB \# 118 & 2304 & 1437 & 3773 & 3315 & 3393 & 2724 & 10741 & 1981 \\
\hline PCB \# 123 & 61.1 & 105 & 231 & 132 & 422 & 252 & 428 & 262 \\
\hline PCB \# 156 & 318 & 258 & 756 & 517 & 654 & 537 & 1276 & 321 \\
\hline PCB \# 157 & 54.7 & 34.7 & 120 & 109 & 109 & 95.7 & 287 & 61.8 \\
\hline PCB \# 167 & 405 & 335 & 851 & 615 & 874 & 569 & 1986 & 425 \\
\hline PCB \# 189 & 47.8 & 56.0 & 158 & 66.2 & 124 & 76.3 & 80.1 & 62.0 \\
\hline WHO-TEQ ${ }_{\mathrm{PCB}}$ & 3.00 & 1.86 & 4.75 & 3.42 & 4.63 & 3.26 & 6.62 & 6.30 \\
\hline \multicolumn{9}{|l|}{ Indicator } \\
\hline $\mathrm{PCB} \# 28$ & 3.26 & 1.80 & 4.41 & 2.68 & 3.62 & 5.88 & 2.69 & 2.29 \\
\hline $\mathrm{PCB} \# 52$ & 3.04 & 2.71 & 4.28 & 3.22 & 3.38 & 4.44 & 8.92 & 3.18 \\
\hline PCB \# 101 & 4.27 & 4.01 & 9.01 & 7.35 & 5.47 & 4.17 & 15.1 & 3.32 \\
\hline PCB \# 118 & 2.30 & 1.44 & 3.77 & 3.32 & 3.39 & 2.72 & 10.7 & 1.98 \\
\hline PCB \# 153 & 4.26 & 4.78 & 10.9 & 8.06 & 11.7 & 8.86 & 12.7 & 7.36 \\
\hline PCB \# 138 & 3.38 & 3.75 & 7.97 & 5.93 & 11.7 & 8.22 & 17.1 & 5.93 \\
\hline PCB \# 180 & 2.89 & 4.23 & 9.55 & 6.56 & 9.48 & 5.73 & 5.27 & 3.94 \\
\hline Total & 23.42 & 22.7 & 49.9 & 37.1 & 48.7 & 40.0 & 72.5 & 28.0 \\
\hline
\end{tabular}


Table 3

Variations in PCDD, PCDF and PCB concentrations between sewage sludge samples in the 80s, 90s and 2000.

\begin{tabular}{lccc}
\hline WWTPs & $80 \mathrm{~s}$ & $90 \mathrm{~s}$ & 2000 \\
\hline pg TEQPCDD/F d.w. & & & \\
\hline Figueres & $277^{\mathrm{a}}$ & $22.5^{\mathrm{a}}$ & 20.8 \\
Olot & $1028^{\mathrm{a}}$ & $7.76^{\mathrm{a}}$ & 5.43 \\
Roses & $78.2^{\mathrm{a}}$ & $13.1^{\mathrm{a}}$ & 7.18 \\
Tossa & $99.4^{\mathrm{a}}$ & $158^{\mathrm{a}}$ & 4.90 \\
Vilafranca & $55.5^{\mathrm{a}}$ & $108^{\mathrm{a}}$ & 7.18 \\
\hline ng PCB/g d.w. & & & \\
\hline Figueres & & & 23.4 \\
Reus & $62.1^{\mathrm{b}}$ & 40.0 \\
Roses & & $653^{\mathrm{c}}$ & 49.9 \\
Tossa & $121^{\mathrm{b}}$ & & 37.1 \\
Vilafranca & & $69^{\mathrm{c}}$ & \\
\hline
\end{tabular}

* expressed as a $\sum$ of PCB 28, 52, 101, 118, 153, 138 and 180

${ }^{a}$ Results from Eljarrat et al. (1999)

${ }^{\mathrm{b}}$ Results from Eljarrat et al. (1997)

${ }^{c}$ Results from Pauné et al. (1994) 
Figure 1

Percentage contribution to the total WHO-TEQ from non-ortho and mono-ortho PCBs, and PCDDs/Fs.

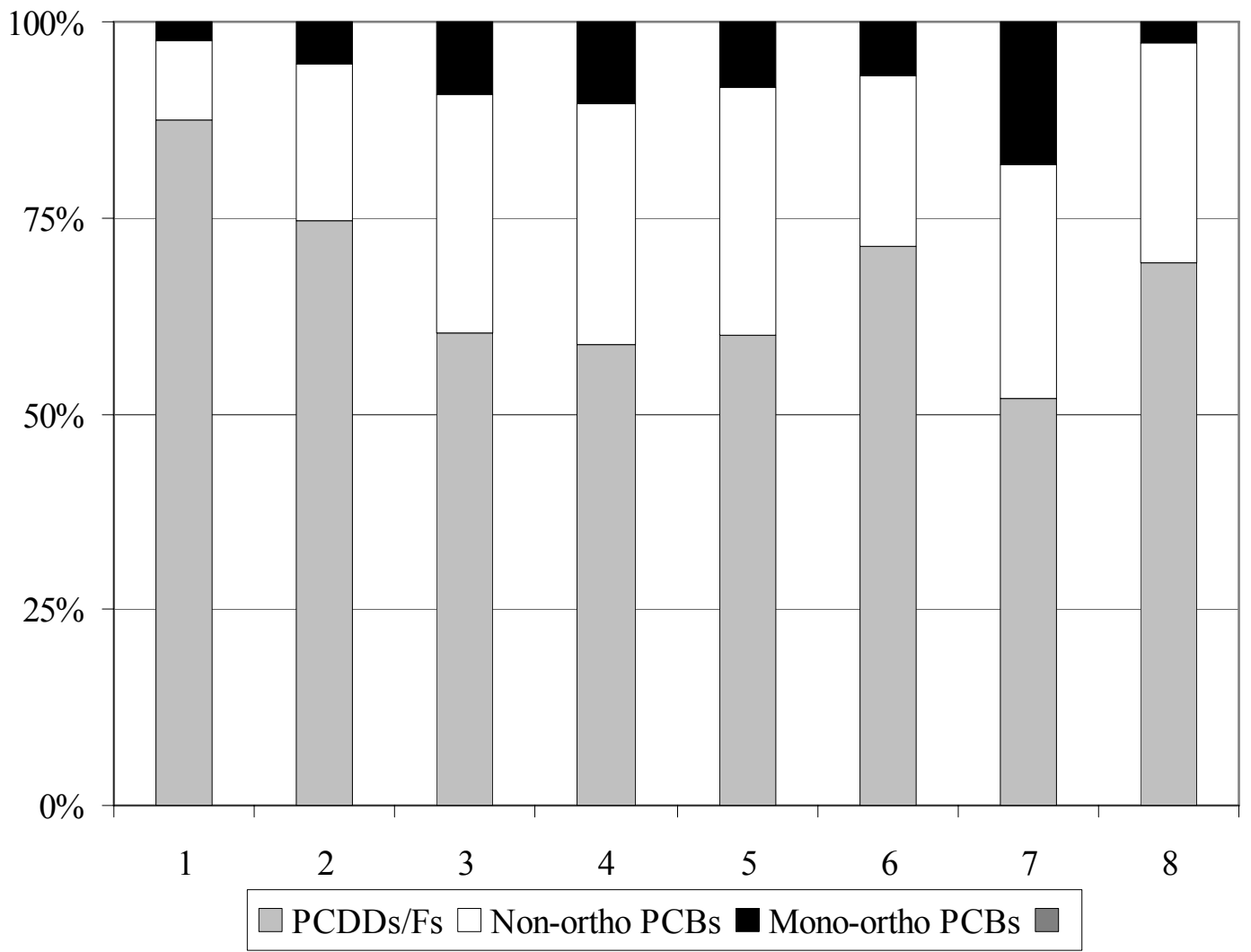


